Abstract THU0110 -Table 1.

Table 1. Baseline characteristics of the matched RA cohort

\begin{tabular}{|c|c|c|}
\hline & $\begin{array}{c}\text { Patients with } \\
\text { RA + SS } \\
(n=283)\end{array}$ & $\begin{array}{l}\text { Patients with RA only } \\
\qquad(n=283)\end{array}$ \\
\hline Age, years, mean $(S D)$ & $58.4(12.2)$ & $58.7(12.8)$ \\
\hline Sex, female & $235(83.0)$ & $235(83.0)$ \\
\hline Duration of RA, years, mean (SD) & $10.5(10.0)$ & $10.3(9.7)$ \\
\hline \multicolumn{3}{|l|}{ Co-morbidities } \\
\hline CV disease ${ }^{x}$ & $32(11.3)$ & $31(11.0)$ \\
\hline Malignancy ${ }^{\dagger}$ & $29(10.2)$ & $31(11.0)$ \\
\hline Serious infections ${ }^{\ddagger}$ & $24(8.5)$ & $24(8.5)^{\prime}$ \\
\hline Anti-cyclic citrullinated peptide,$+ n / m(\%)$ & $56 / 114(49.1)$ & $66 / 119(55.5)$ \\
\hline $\mathrm{RF}+, \mathrm{n} / \mathrm{m}(\%)$ & $91 / 137(66.4)$ & $80 / 144(55.6)$ \\
\hline Erosive disease, $\mathrm{n} / \mathrm{m}(\%)$ & $74 / 216(34.3)$ & $64 / 197(32.5)$ \\
\hline Subcutaneous nodules, $\mathrm{n} / \mathrm{m}(\%)$ & $69 / 283(24.4)$ & $73 / 283(25.8)$ \\
\hline CDAl score, mean (SD) & $24.0(14.9)$ & $24.1(14.7)$ \\
\hline \multicolumn{3}{|l|}{ Number of prior b/tsDMARDs } \\
\hline 0 & $116(41.0)$ & $121(42.8)$ \\
\hline 1 & $77(27.2)$ & $70(24.7)$ \\
\hline$\geq 2$ & $90(31.8)$ & $92(32.5)$ \\
\hline \multicolumn{3}{|l|}{ Number of prior csDMARDs } \\
\hline & $16(5.7)$ & $16(5.7)$ \\
\hline 1 & $116(41.0)$ & $110(38.9)$ \\
\hline$\geq 2$ & $151(53.4)$ & $157(55.5)$ \\
\hline
\end{tabular}

tory of coronary artery disease, myocardial infarction, congestive heart failure requiring yndrome, unstable angina, cardiac revascularisation procedure, cardiac arrest, ventricular arrhythmia, stroke, transient ischemic attack or other $\mathrm{CV}$ event

tHistory of lung cancer, breast cancer, lymphoma, skin cancer (melanoma and squamous cell carcinoma) or other cancer

FInfection required hospitalisation or IV treatment

b/tsDMARD=biogic or targeted synthetic DMARD; csDMARD=conventional synthetic

b/tsDMARD=biologic or targeted synthetic DMARD; $c$ DDMARD=conventional synthetic
DMARD; $\mathrm{CV}=$ cardiovascular; $n / m=$ number of patients/total number of patients with available

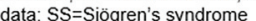

Abstract THU0110 -Table 2

Table 2. Mean (SD) change in CDAl score and PROs from index visit to 12 month follow-up visit

\begin{tabular}{|c|c|c|c|}
\hline 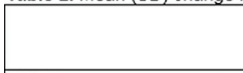 & $\begin{array}{l}\text { Patients with } \\
\text { SS + RA } \\
(n=283)\end{array}$ & $\begin{array}{l}\text { Patients with } \\
\text { RA only } \\
\text { (n=283) }\end{array}$ & p value ${ }^{*}$ \\
\hline CDAl & $8.8(14.6)$ & $9.3(14.3)$ & 0.704 \\
\hline Patient pain & $6.5(29.2)$ & $14.0(28.0)$ & 0.002 \\
\hline Patient fatigue & $4.3(29.9)$ & $13.0(29.9)$ & 0.001 \\
\hline Patient global assessment & $5.5(29.1)$ & $13.0(28.5)$ & 0.002 \\
\hline Morning stiffness (min) & $19.8(245.2)$ & $21.2(250.7)$ & 0.947 \\
\hline
\end{tabular}

Results: After PSM, baseline characteristics in 283 pairs of pts with and without SS were well balanced (Table 1). Mean change in CDAI score was numerically lower in SS than non-SS pts (8.8 vs 9.3; Table 2), but this did not reach statistical significance. Improvements in pain, fatigue and stiffness were 2-2.5-fold greater for non-SS than SS pts (Table 2). Conclusion: Among those initiating b/tsDMARD treatment, improvements in RA-related PROs were lower in pts with RA with SS than non-SS pts. Physicians may want to consider SS status secondary to RA when managing pts with RA and specifically explore whether additional intervention is needed to improve the pt experience for pts with RA.

REFERENCES:

[1] Harrold LR, et al. Arthritis Rheumatol. 2018;70(suppl 10): abstract 541.

Acknowledgement: This study was sponsored by Corrona, LLC. Corrona is supported through contracted subscriptions with multiple pharmaceutical companies. The abstract was a collaborative effort between Corrona and Bristol-Myers Squibb (BMS) with financial support provided by BMS. Professional medical writing: Lola Parfitt, MRes, Caudex; funding: BMS

Disclosure of Interests: Leslie R Harrold Shareholder of: Corrona LLC, Grant/research support from: Grant funding: Pfizer, Consultant for: AbbVie, Bristol-Myers Squibb, Genentech, Employee of: Corrona LLC, Ying Shan Employee of: Corrona LLC, Sabrina Rebello Employee of: Corrona, LLC, Neil Kramer Shareholder of: Johnson \& Johnson, Pfizer, Regeneron, AbbVie, Amgen, Sean Connolly Shareholder of: Bristol-Myers Squibb, Employee of: Bristol-Myers Squibb, Evo Alemao Shareholder of: BristolMyers Squibb, Employee of: Bristol-Myers Squibb, Sheila Kelly Shareholder of: Bristol-Myers Squibb, Employee of: Bristol-Myers Squibb, Joel Kremer Grant/research support from: AbbVie, Genentech, Lilly, Novartis, Pfizer, Consultant for: AbbVie, Amgen, BMS, Genentech, Lilly, Regeneron, Sanofi, Pfizer, Elliot D Rosenstein Grant/research support from: AbbVie, Novartis, Consultant for: Amgen, Bristol-Myers Squibb, Boehringer Ingelheim, Speakers bureau: Amgen, Bristol-Myers Squibb

DOI: 10.1136/annrheumdis-2019-eular.1957

\section{THU0111 ANGIOGENIC T CELLS AS AN INDEPENDENT PREDICTOR OF VASCULAR STIFFNESS IN VERY EARLY RHEUMATOID ARTHRITIS}

Javier Rodríguez-Carrio ${ }^{1,2}$, Mercedes Alperi-López $^{3}$, Patricia López ${ }^{1}$, Ángel PérezÁlvare $z^{4}$, Lorena Benavente ${ }^{4}$, Francisco Javier Ballina-García ${ }^{3}$, Ana Suárez ${ }^{1}$.

${ }^{1}$ University of Oviedo, ISPA, Area of Immunology, Oviedo, Spain; ${ }^{2}$ Hospital Universitario Central de Asturias, Bone and Mineral Research Unit, Instituto Reina Sofía de Investigación Nefrológica, REDinREN del ISCIII, Oviedo, Spain; ${ }^{3} \mathrm{Hospital}$ Universitario Central de Asturias, Department of Rheumatology, Oviedo, Spain

${ }^{4}$ Hospital Universitario Central de Asturias, Department of Neurology, Oviedo, Spain

Background: Angiogenic $\mathrm{T}$ cells (Tang) are responsible of vascular repair and homeostasis. Decreased Tang frequencies have been reported in rheumatoid arthritis (RA), in association with disease activity and previous history of cardiovascular (CV) disease. However, excess of CV risk is already present during the early stage of RA. Whether Tang cells are associated with subclinical vascular abnormalities remains unknown.

Objectives: To evaluate whether Tang cells could be associated with subclinical CV endpoints (subclinical atherosclerosis and vascular stiffness) in the very early stage of RA.

Methods: Patients were recruited upon early referral to the rheumatology department. All patients were untreated at the time of sampling. Tang (CD3+CD31+CXCR4+) frequency was assessed by flow cytometry in peripheral blood samples. Plaque occurrence, cIMT and stiffness parameters were analyzed by Doppler ultrasound in internal carotid, middle cerebral and basilar arteries.

Results: 53 patients were recruited, 47 fulfilling 2010 ACR/EULAR classification criteria for RA (36 women, $26 \mathrm{FR}+$ and $26 \mathrm{ACPA}+$ ) and 6 fulfilling criteria for Clinically Suspect Arthralgia (CSA) (6 women, $3 \mathrm{RF}+$ and 2 ACPA+). Tang frequency did not differ between RA and CSA $(p=0.382$ and it was negatively associated with DAS28 $(r=-0.448, p<0.001)$ and SDAI $(r=-0.385, p=0.006)$, but not with duration of the symptoms $(r=0.053, p=0.713))$. Tang levels were not related to individual traditional $\mathrm{CV}$ risk factors, body mass index, wait circumference (all $\mathrm{p}>0.050$ ) nor with the modified SCORE $(r=-0.173, p=0.244)$ or Framingham Risk Score $(r=-0.127, p=0.399)$. Neither atherosclerosis plaque occurrence $(r=0.631)$ nor the cIMT ( $r=0.070, p=0.652)$ were associated with Tang levels.

Tang frequency paralleled carotid peak systolic velocity $(r=0.399, p=0.008$ and end diastolic velocity $(r=0.332, p=0.034)$ in internal carotid artery Moreover, Tang positively correlated stiffness parameters: vascular strain (VS, $r=0.428, p=0.010$ ), vascular distensibility (VD, $r=0.479, p=0.004$ ), vascular stiffness (VSf, $r=-0.519, p<0.001$ ) and pressure-strain elastic modulus (PSEM, $r=-0.531, p<0.015)$ in left internal carotid artery. Finally, Tang frequency was an independent predictor of stiffness parameters after adjusting for mSCORE, body mass index, DAS28, RF and ACPA positivity: VS $(\beta=0.451, p=0.045)$, VD $(\beta=0.462, p=0.026)$, VSf $(\beta=-0.422, p=0.035)$ and PSEM ( $\beta=-0.446, p=0.026)$.

Conclusion: Tang cells may have a very early role on vascular stiffness in RA. These results point to the Tang subset as the missing link between disease activity and vascular abnormalities during the first stage of the disease.

Disclosure of Interests: None declared

DOI: 10.1136/annrheumdis-2019-eular.2647

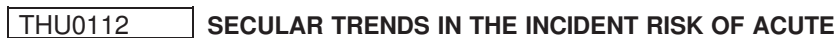 MYOCARDIAL INFARCTION IN RHEUMATOID ARTHRITIS RELATIVE TO THE GENERAL POPULATION}

Kiana Yazdani, Hui Xie, Antonio Aviña, Yufei Zheng, Michal Abrahamowicz, Diane Lacaille. Arthritis Research Canada, Richmond, Canada

Background: Recent studies have demonstrated a declining trend in RA mortality relative to the general population (1). This improvement in mortality could be due to improvement in incident risk of cardiovascular events that are the leading cause of excess deaths in RA (2).

Objectives: Our objective was to assess secular trends in ten-year incident risk of acute myocardial infarction (AMI) in incident cohorts of RA versus general population controls, using administrative health data.

Methods: We conducted a retrospective study of a population-based cohort of incident RA cases who first met previously published RA criteria between 01/01/1997 and 31/12/2004 in British Columbia, followed until $12 / 2014$, with general population controls matched $2: 1$ on gender, age, and index year. Individuals were excluded if they had a diagnosis of $\mathrm{Ml}$ prior to index date. Incident AMI was defined as first AMl during followup using ICD codes (ICD-9 code 410/ICD-10 code I21) in Hospital Discharge data or death certificate in Vital Statistics data. RA and general population cohorts were stratified according to year of RA incidence, 